\title{
Adenine Nucleotides and 5-Hydroxytryptamine Released by Aggregating Platelets Inhibit Adrenergic Neurotransmission in Canine Coronary Artery
}

Richard A. Cohen

With the technical assistance of Kevin M. Zitnay, Robert M. Weisbrod, and Richard K. Grady

Robert Dawson Evans Memorial, Department of Clinical Research, Peripheral Vascular Section, University Hospital,

Boston University Medical Center, Boston, Massachusetts 02118

\begin{abstract}
The purpose of this study was to determine the effect of vasoactive substances released by aggregating platelets on adrenergic neurotransmission in canine coronary arteries. Isometric tension was recorded in isolated ring segments of coronary artery denuded of endothelium and the release of $\left[{ }^{3} \mathrm{H}\right]$ norepinephrine was measured from strips of coronary artery preincubated with the radiolabeled transmitter. Transmural electrical field stimulation and exogenously added norepinephrine caused beta adrenergic relaxations of coronary rings contracted by prostaglandin $F_{2 \alpha}$. In coronary rings further contracted by the addition of aggregating platelets in numbers less than that present in blood, the response to electrical stimulation was inhibited and the sensitivity to norepinephrine reduced. Micromolar concentrations of adenosine diphosphate, adenosine triphosphate, and 5-hydroxytryptamine were released by platelets under these experimental conditions. The reduced response to electrical stimulation was in part due to inhibition of the stimulated release of $\left[{ }^{3} \mathrm{H}\right]-$ norepinephrine. The combination of the serotonergic antagonist, methiothepin, and the purinergic antagonist, theophylline, attenuated the inhibition of the responses of coronary rings; either antagonist alone failed to do so, but did significantly block the reductions caused by 5-hydroxytryptamine and adenosine diphosphate, respectively. In addition, only the combination of the two antagonists significantly attenuated the inhibition of norepinephrine release caused by platelets. These data suggest that both adenine nucleotides and 5-hydroxytryptamine are important mediators of the prejunctional and postjunctional inhibition of coronary beta adrenergic neurotransmission caused by platelets.
\end{abstract}

\section{Introduction}

Platelets aggregate at sites of damage to the vascular endothelium (1). The release of vasoactive substances by the platelets may influence the smooth muscle of the arterial wall. Coronary arterial endothelial cells may respond to platelet-released 5-hydroxytryptamine and adenine nucleotides and cause relaxation of isolated coronary smooth muscle $(2-5)$. If the endothelium is damaged, 5-hydroxytryptamine $(2,3,6)$ and thromboxane $A_{2}$ (7) released by aggregating platelets have been shown to contract coronary arteries. Beta adrenergic neurotransmission which has been demonstrated in isolated epicardial canine coronary arteries (8) would be expected to oppose the contractile influence exerted

Received for publication 3 April 1985 and in revised form 3 October 1985.

J. Clin. Invest.

(c) The American Society for Clinical Investigation, Inc. 0021-9738/86/02/0369/07 \$1.00

Volume 77, February 1986, 369-375 by platelets. A previous study has demonstrated, however, that after exposure of canine coronary arteries to aggregating platelets, neurogenic serotonergic contractions resulted from accumulation of 5-hydroxytryptamine in the adrenergic nerve endings (9). The present study was performed to further determine the effects on adrenergic neurotransmission in canine coronary artery during exposure to aggregating platelets.

\section{Methods}

The heart was removed from mongrel dogs after anesthesia with sodium pentobarbital ( $30 \mathrm{mg} / \mathrm{kg}$, i.v.) and exsanguination; the epicardial coronary arteries were immediately dissected free.

Organ bath experiments. Rings of left circumflex artery $6 \mathrm{~mm}$ in length were studied in organ chambers $(25 \mathrm{ml})$ filled with physiological salt solution of the following millimolar composition: $\mathrm{NaCl}, 118.3 ; \mathrm{KCl}$, 4.7; $\mathrm{MgSO}_{4}, 0.6 ; \mathrm{KH}_{2} \mathrm{PO}_{4}, 1.2 ; \mathrm{CaCl}_{2}, 2.5 ; \mathrm{NaHCO}_{3}, 25.0$; calcium EDTA, 0.026; and glucose, 11.1. The solution was maintained at $37^{\circ} \mathrm{C}$ and gassed with $95 \% \mathrm{O}_{2} ; 5 \% \mathrm{CO}_{2}$. In order to eliminate endotheliumdependent relaxation caused by aggregating platelets (2), the endothelium was removed from the rings by light mechanical abrasion of the intimal surface. Functional absence of endothelium was confirmed by failure of the ring contracted with prostaglandin $F_{2}$ to relax in response to acetylcholine $\left(10^{-6} \mathrm{M}\right)$. The rings were connected to a strain gauge and resting tension was increased over $90 \mathrm{~min}$ to that which is optimal for contraction (8). Transmural electrical stimulation of adrenergic nerves was accomplished with parallel platinum electrodes, a stimulator, and a direct current amplifier. Optimal nerve stimulation parameters $(10 \mathrm{~V}, 0.1-0.3 \mathrm{~ms}$ pulse duration) were determined in each experiment such that responses to electrical stimulation were abolished by tetrodotoxin $\left(10^{-7} \mathrm{M}\right.$; reference 8). Rings were contracted with prostaglandin $\mathrm{F}_{2 \alpha}\left(2 \times 10^{-6} \mathrm{M}\right)$ in order to study relaxation responses. Responses to increasing frequencies $(0.5-$ $16 \mathrm{~Hz}$ ) were allowed to reach maximum before the frequencies were increased. All experiments were performed in the presence of indomethacin $\left(3 \times 10^{-5} \mathrm{M}\right.$; reference 8$)$ and cocaine $\left(3 \times 10^{-5} \mathrm{M}\right)$.

Protocol. Two responses to electrical stimulation $\left(S_{1} \text { and } S_{2}\right)^{1}$ were obtained in each ring contracted by prostaglandin $F_{2 \alpha}$. After $S_{1}$ and before $\mathrm{S}_{2}$, the ring was rinsed for $1 \mathrm{~h}$ and exposed for $20 \mathrm{~min}$ to either aggregating platelets, adenosine diphosphate $\left(3 \times 10^{-6} \mathrm{M}\right)$, or 5 -hydroxytryptamine $\left(3 \times 10^{-6} \mathrm{M}\right)$ before addition of prostaglandin $\mathrm{F}_{2 \alpha}$. Indomethacin was omitted before adding platelets, and re-added when the contraction caused by platelets had stabilized. After the later response to electrical stimulation, the tension was allowed to stabilize and norepinephrine or sodium nitroprusside was added to the organ chamber in cumulative half-log unit increments. The effects of antagonists were determined in rings in which the antagonist was present for $20 \mathrm{~min}$ before $S_{1}$ and thereafter present throughout. No antagonist affected resting tension of the coronary artery rings.

Data analysis. The relaxations in response to electrical stimulation and norepinephrine were expressed as a percentage of the tension above baseline immediately before each response to electrical stimulation or norepinephrine. The ratio of two responses of each ring to each frequency

1. Abbreviations used in this paper: $\mathrm{IC}_{50}$, concentration causing $50 \%$ relaxation; $S_{1}, S_{2}, S_{3}$, three responses to electrical stimulation. 
of stimulation were compared to determine the effect of platelets, adenosine diphosphate, or 5-hydroxytryptamine (9-11). The sensitivity to norepinephrine or sodium nitroprusside was determined by graphic estimation of the concentration that caused $50 \%$ relaxation (IC $\mathrm{I}_{\mathbf{0}}$; reference 8).

$\left[{ }^{3} \mathrm{H}\right]$ Norepinephrine overflow. Longitudinal strips of coronary artery were incubated for $120 \mathrm{~min}$ in $\left[{ }^{3} \mathrm{H}\right]$ norepinephrine $\left(10^{-7} \mathrm{M}\right)$ and superfused as previously described $(8,10,11)$. In brief, the strips were mounted between two platinum wires for electrical stimulation $(10 \mathrm{~V}, 0.2 \mathrm{~ms}, 2$ $\mathrm{Hz}$ ) and superfused at $3 \mathrm{ml} / \mathrm{min}$ with oxygenated physiological salt solution at $37^{\circ} \mathrm{C}$.

Protocol. After an initial washout period of $120 \mathrm{~min}$, the superfusate was collected for 2-min intervals for determination of the overflow from the tissue of tritiated compounds. The strips were stimulated three times for $6 \mathrm{~min}, 30 \mathrm{~min}$ apart $\left(\mathrm{S}_{1}-\mathrm{S}_{3}\right)$; in some experiments, aggregating platelets or adenosine diphosphate $\left(3 \times 10^{-6} \mathrm{M}\right)$ were added to the superfusate for $15 \mathrm{~min}$ before and during $\mathrm{S}_{2}$. The effects of antagonists were determined in strips exposed to the drugs throughout the washout and stimulations. No antagonist affected the basal release of $\left[{ }^{3} \mathrm{H}\right]$ norepinephrine. The superfusate collected before and during electrical stimulation was collected in tubes containing $5 \mathrm{~N} \mathrm{HCl}$ resulting in a final concentration of $1 \mathrm{~N}$. In these samples, total $\left[{ }^{3} \mathrm{H}\right]$ norepinephrine which overflowed from the tissue was separated from its major metabolites by ion exchange chromatography $(12,13)$.

Data analysis. Basal overflow of $\left[{ }^{3} \mathrm{H}\right]$ norepinephrine was calculated as disintegrations per minute per milligrams tissue collected during the 6-min before electrical stimulation. Stimulation-evoked overflow of $\left[{ }^{3} \mathrm{H}\right]$ norepinephrine was calculated as the overflow collected during the 6-min stimulation minus the basal overflow. The effect of aggregating platelets and adenosine diphosphate on stimulation-evoked overflow of $\left[{ }^{3} \mathrm{H}\right]$ norepinephrine was assessed by comparing the actual evoked release during $S_{2}$ with that expected. The expected release during $S_{2}$ was calculated by an average of the evoked release during $S_{1}$ and $S_{3}$ and results are expressed as percent change from expected release. In strips stimulated three times but treated with control solution throughout, the expected and actual evoked release of $\left[{ }^{3} \mathrm{H}\right]$ norepinephrine during $S_{2}$ were not significantly different $(+3.0 \pm 3.7 \%$ change from expected; reference 11$)$.

Platelet preparation. Autologous blood was collected in modified acid/ citrate/dextrose anticoagulant (2). Platelet-rich plasma was obtained by centrifugation $(180 \mathrm{~g}, 20 \mathrm{~min})$. A platelet pellet was obtained $(1600 \mathrm{~g}$, $10 \mathrm{~min}$ ), resuspended, and washed once in calcium-free saline containing $0.4 \%$ citrate at $\mathrm{pH} 6.5$. The number of platelets in these suspensions was counted with a Coulter counter (Coulter Electronics Inc., Hialeah, FL) and suspensions were added to the physiological salt solution resulting in a final concentration of $4.5 \pm 0.5 \times 10^{4}$ platelets $/ \mu \mathrm{l}(n=16)$. A sample of these platelet preparations contained 1 white cell for every 300 platelets. The same concentrations of platelets were used in the organ bath experiments as were employed in those experiments in which $\left[{ }^{3} \mathrm{H}\right]$ norepinephrine release was measured.

Determination of 5-hydroxytryptamine. 5-Hydroxytryptamine was quantitated in aliquots of the organ chamber contents removed after the second response to electrical stimulation. Samples were frozen at $-20^{\circ} \mathrm{C}$ before assay; no significant decomposition of frozen standards occurred. Measurement was by way of reverse-phase microbore high pressure liquid chromatography and electrochemical detection (14). Chromatographic separation of $5-\mu$ l injections was accomplished on a $10 \mathrm{~cm} \times 1.2 \mathrm{~mm}$ i.d. column slurry packed with Hypersphere $3-\mu \mathrm{m}$ octadecylsilane $\left(C_{18}\right)$ (Shandon Southern Instruments Inc., Sewickley, PA). The solvent consisted of $0.1 \mathrm{M}$ sodium acetate, $0.1 \mathrm{M}$ acetic acid, and $3 \%$ (vol/vol) acetone, $\mathrm{pH} 4.5$; a flow rate of $100-125 \mu \mathrm{l} / \mathrm{min}$ was maintained by way of a pulseless, fast reciprocating pump (Applied Chromatography Systems, Inc., State College, PA). Amperometric detection was accomplished with a glassy carbon electrode (+0.6 V) and an LC-4B detector (Bioanalytical Systems Inc., W. Lafayette, IN). Quantitation and retention times were compared with authentic standard. With this system, chromatograms of samples of platelet-released products contained only one peak which had a retention time identical to that of 5-hydroxytryptamine.
Determination of adenine nucleotides. Adenine nucleotides were assayed in the same aliquots of the organ chamber contents as was 5-hydroxytryptamine by modification of the luciferase bioluminescent technique (15). Adenosine diphosphate was converted to adenosine triphosphate with pyruvate kinase and phosphoenolpyruvate and total adenine nucleotides quantitated. The reported value for adenosine diphosphate was the difference between the total and adenosine triphosphate measured.

Drugs. The following pharmacological agents were used: cocaine hydrochloride (generic); acetylcholine chloride, adenosine diphosphate, 5-hydroxytryptamine creatinine sulfate, indomethacin, 1-norepinephrine bitartrate, prostaglandin $F_{2 \alpha}$ (Tris salt), and theophylline (Sigma Chemical Co., St. Louis, MO); methiothepin maleate (Hoffman-LaRoche Inc., Nutley, NJ); and sodium nitroprusside (Fisher Scientific Co., Allied Corp., Pittsburgh, PA).

Statistical analysis. The data were expressed as means \pm SEM. Statistical evaluation of the data was by Student's $t$ test for unpaired or paired comparisons. $n$ refers to the number of animals from which tissues were used. $P$ values $<0.05$ were regarded significant.

\section{Results}

Effect of aggregating platelets, adenosine diphosphate, and 5-hydroxytryptamine on response of coronary artery to electrical stimulation and norepinephrine. In the presence of cocaine $\left(3 \times 10^{-5} \mathrm{M}\right)$, electrical stimulation $\left(\mathrm{S}_{1}\right)$ caused frequency-dependent relaxations of rings of left circumflex coronary artery contracted by prostaglandin $\mathrm{F}_{2 \alpha}\left(2 \times 10^{-6} \mathrm{M}\right.$, Fig. 1). When prostaglandin $F_{2 \alpha}$ was added to coronary rings contracted by aggregating platelets before $S_{2}$, the resulting tension was significantly greater than that resulting from the prostaglandin alone (Table I). Compared with rings contracted by prostaglandin $\mathrm{F}_{2 a}$ alone, the relaxations caused by electrical stimulation from 0.5 to $16 \mathrm{~Hz}$ were significantly attenuated in the rings contracted in addition by aggregating platelets (Fig. 1, Table I). The relaxation in response to $2-\mathrm{Hz}$ stimulation was reduced from $64 \pm 14 \%$ of tension induced by prostaglandin $F_{2 \alpha}$ to $6.7 \pm 1.3 \%$ in rings contracted by platelets in addition to prostaglandin $F_{2 \alpha}(P$ $<0.001)$. The sensitivity to exogenously added norepinephrine was also significantly reduced by the addition of platelets (Table I). The relaxation in response to $3 \times 10^{-8} \mathrm{M}$ norepinephrine was reduced from $69 \pm 13 \%$ in rings contracted by prostaglandin $\mathrm{F}_{2 \alpha}$ alone, to $10 \pm 1.1 \%$ in rings exposed to platelets $(P<0.001)$. A similar decrease in sensitivity to sodium nitroprusside occurred

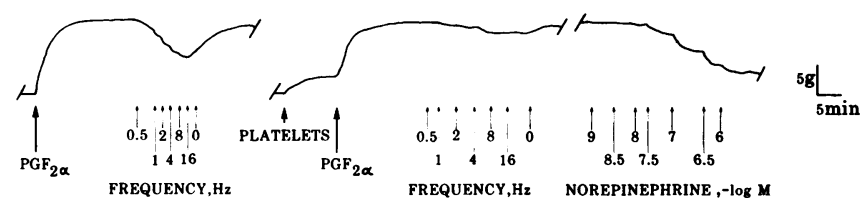

Figure 1. Sample tracing of the experimental protocol used to study the effect of platelets on beta adrenergic neurotransmission in canine coronary artery. After contracting the ring to prostaglandin $F_{2 a}$ $\left(\mathrm{PGF}_{2 \alpha}, 2 \times 10^{-6} \mathrm{M}\right)$, a response to transmural electrical stimulation $\left(0.5-16 \mathrm{~Hz}, \mathrm{~S}_{1}\right)$ was obtained. After washing the preparation for $1 \mathrm{~h}$, platelets were added to the organ chamber and the resulting contraction allowed to stabilize, before adding prostaglandin $F_{2 \alpha}$ and obtaining a second response to electrical stimulation $\left(\mathrm{S}_{2}\right)$. Following the second response to electrical stimulation, the concentration of norepinephrine in the organ chamber was increased in half-log unit increments $\left(10^{-9}-10^{-6} \mathrm{M}\right)$. Control rings which were not exposed to platelets and rings which were treated with antagonists throughout were run simultaneously in adjacent organ chambers. 


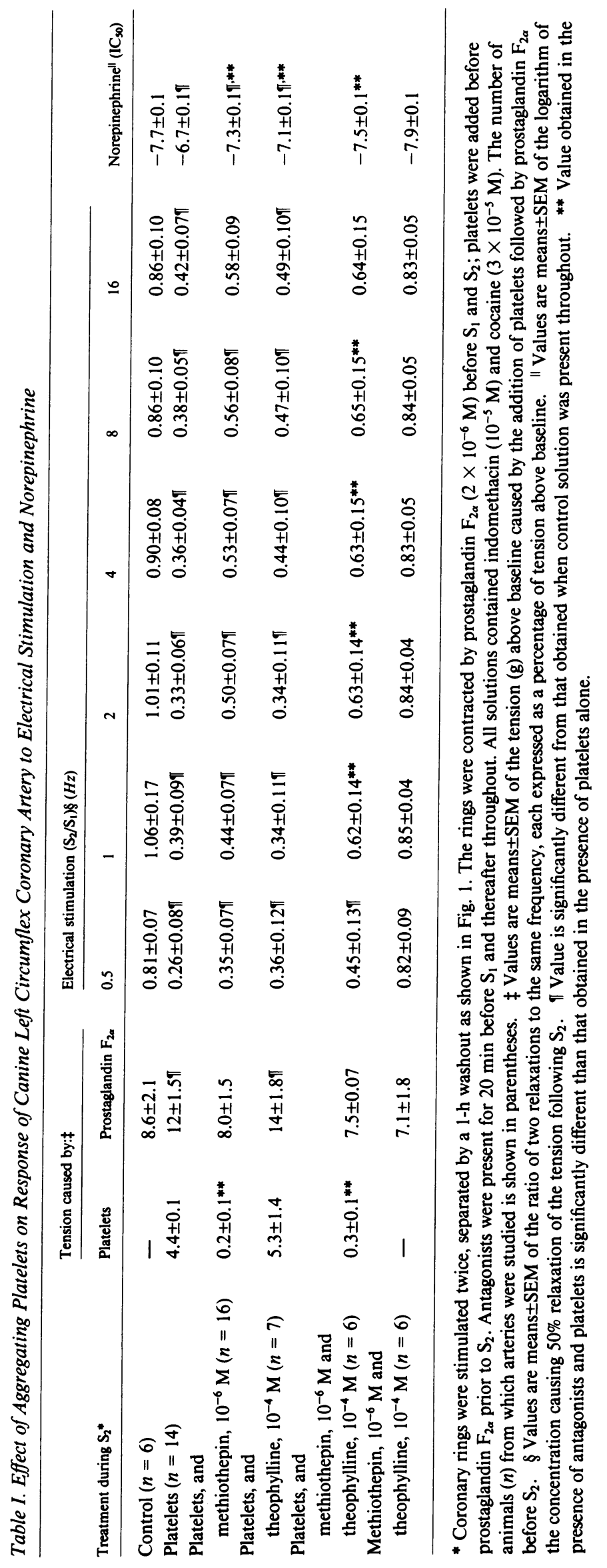


in rings contracted by platelets compared with rings contracted by prostaglandin $\mathrm{F}_{2 \alpha}$ alone (log $\mathrm{IC}_{50}$ : control solution, $-7.78 \pm 0.12$; platelets $-7.25 \pm 0.11 ; n=6, P<0.05)$. Adenosine diphosphate $\left(3 \times 10^{-6} \mathrm{M}\right)$ and 5-hydroxytryptamine $\left(3 \times 10^{-6}\right.$ M) also significantly attenuated the relaxation in response to electrical stimulation and the sensitivity to norepinephrine of coronary artery rings (Table II).

In strips of coronary artery preincubated in $\left[{ }^{3} \mathrm{H}\right]-$ norepinephrine and superfused with physiological salt solution containing cocaine $\left(3 \times 10^{-5} \mathrm{M}\right)$, aggregating platelets added to the superfusate caused no significant change in the basal overflow of $\left[{ }^{3} \mathrm{H}\right]$ norepinephrine (Fig. 2). Aggregating platelets did significantly inhibit the overflow of $\left[{ }^{3} \mathrm{H}\right]$ norepinephrine caused by 2 $\mathrm{Hz}$ electrical stimulation by $33 \pm 6 \%$ (Fig. 2). Adenosine diphosphate $\left(3 \times 10^{-6} \mathrm{M}\right)$ also significantly reduced the overflow of $\left[{ }^{3} \mathrm{H}\right]$ norepinephrine caused by $2 \mathrm{~Hz}$ by $28 \pm 5 \%(n=3)$.

Effects of antagonists on the inhibitory actions of aggregating platelets, adenosine diphosphate, and 5-hydroxytryptamine in coronary artery. The combination of methiothepin $\left(10^{-6} \mathrm{M}\right)$ and theophylline $\left(10^{-4} \mathrm{M}\right)$ significantly reduced the inhibition caused by platelets of the relaxation of coronary artery rings from 1 to $8 \mathrm{~Hz}$ (Table I). Neither antagonist alone prevented the inhibitory action of platelets on the response of coronary artery rings to electrical stimulation. Methiothepin or theophylline each partially blocked the platelet-induced reduction in sensitivity of coronary rings to exogenous norepinephrine, whereas the combination restored the sensitivity to the control value. The combination of the two antagonists in the absence of platelets did not significantly affect the ratio of the responses to electrical stimulation $\left(S_{2} / S_{1}\right)$ or the sensitivity to norepinephrine (Table I). Methiothepin, alone or in combination with theophylline, blocked the contractile response to platelets (Table I).

Theophylline $\left(10^{-4} \mathrm{M}\right)$ significantly blocked the reduction in the response of coronary rings to $2-\mathrm{Hz}$ electrical stimulation caused by adenosine diphosphate $\left(3 \times 10^{-6} \mathrm{M}\right.$, Table II). Methiothepin significantly reduced the inhibition of the response to electrical stimulation caused by 5 -hydroxytryptamine $\left(3 \times 10^{-6}\right.$ $M)$. The antagonists also blocked the reduction in sensitivity to exogenous norepinephrine caused by each agonist. Methiothepin blocked the contractile response to 5-hydroxytryptamine (3 $\times 10^{-6} \mathrm{M}$ ) which resulted in significantly greater tension before $\mathrm{S}_{2}$ in the absence of the antagonist (Table II).

The stimulated overflow of $\left[{ }^{3} \mathrm{H}\right]$ norepinephrine from strips of coronary artery was significantly augmented by methiothepin $\left(10^{-6} \mathrm{M}\right)$ but not by theophylline $\left(10^{-4} \mathrm{M}\right)$; the combination of methiothepin and theophylline resulted in a stimulated overflow which was not significantly different from that caused by methiothepin alone (Table III). Only the combination of methiothepin $\left(10^{-6} \mathrm{M}\right)$ and theophylline $\left(10^{-4} \mathrm{M}\right)$ significantly reduced the inhibitory effect of platelets on the stimulated overflow of $\left[{ }^{3} \mathrm{H}\right]$ norepinephrine (Fig. 3). Neither of these antagonists alone blocked the prejunctional inhibition caused by aggregating platelets.

Theophylline $\left(10^{-4} \mathrm{M}\right)$ significantly attenuated the inhibitory action of adenosine diphosphate $\left(3 \times 10^{-6} \mathrm{M}\right)$ on the overflow of the adrenergic transmitter caused by $2 \mathrm{~Hz}$ from coronary artery to $20 \pm 6 \%(n=3, P<0.01)$.

Concentrations of adenine nucleotides and 5-hydroxytryptamine released by aggregating canine platelets. Under these experimental conditions, platelets released adenosine diphosphate $\left(3.6 \pm 1.1 \times 10^{-6} \mathrm{M}, n=7\right)$, adenosine triphosphate $\left(2.0 \pm 0.7 \times 10^{-6} \mathrm{M}\right)$, and 5-hydroxytryptamine $\left(6.1 \pm 1.2 \times 10^{-7}\right.$ $\mathrm{M})$ into the control physiological salt solution. These values were not significantly different from those obtained in the presence of methiothepin $\left(10^{-6} \mathrm{M}\right)$ and theophylline $\left(10^{-4} \mathrm{M}\right)$.

\section{Discussion}

The action of aggregating platelets on adrenergic neurotransmission in canine coronary artery. Since endothelial cells can cause relaxation of the smooth muscle when exposed to the vasoactive substances released from platelets (2-5), the endothelium was removed from the coronary artery rings in this study so that responses to stimulation of adrenergic nerves could be measured during contractions due to prostaglandin $\mathrm{F}_{2 \alpha}$. Since accumulation of 5-hydroxytryptamine in coronary adrenergic nerves changes the action of the nerves from beta adrenergic relaxation (8) to serotonergic contraction (9), neuronal uptake of 5-hydroxytryptamine was blocked in the present study with cocaine (9) in order to further study the direct effects of substances released from platelets on the nerves.

It is likely that inhibition of beta adrenergic neurotransmission in the coronary artery by aggregating platelets is due in part to limitation of the postjunctional action of neuronally released norepinephrine, since the sensitivity to the exogenously added neurotransmitter was decreased. The greater contractions caused by the addition of platelets may be partly responsible for the attenuated relaxation responses observed. This is suggested by the similar inhibition in the response to exogenously added norepinephrine as was observed in that to the direct smooth muscle relaxant, sodium nitroprusside. That the greater contractions are the sole reason for the limited relaxations to norepinephrine and electrical stimulation is unlikely, since although methiothepin blocked the contractions, the antagonist, when used alone, did not prevent the inhibition caused by platelets.

Although relaxations in response to both norepinephrine and electrical stimulation were attenuated in the presence of platelets, it is also likely that inhibition of norepinephrine release by platelets contributes to the reduction in the response to electrical stimulation. This is suggested by the demonstrated reduction in the overflow of tritiated transmitter from strips of coronary artery stimulated electrically in the presence of platelets.

Role of adenine nucleotides and 5-hydroxytryptamine in inhibiting coronary adrenergic neurotransmission. Adenine nucleotides released from platelets are in part responsible for the inhibition of neurotransmission in the coronary artery. This is suggested by: ( $a$ ) the inhibition of the response of coronary artery rings to exogenous norepinephrine and electrical stimulation by adenosine diphosphate; $(b)$ the demonstrated inhibition by the nucleotide of the overflow of norepinephrine (16); and (c) the release by platelets of vasoactive concentrations of the nucleotides. The rightward shift in the response to norepinephrine caused by adenosine diphosphate cannot be ascribed to contractions, as is the case with platelets; the lower sensitivity may have been mediated by purinergic receptors since theophylline prevented the shift (17). Antagonism by purine compounds of the beta adrenergic chronotropic action of norepinephrine on the heart has been described (18).

Though lower concentrations of 5-hydroxytryptamine than adenosine diphosphate are released by canine platelets, an equimolar amount of the amine was a more potent inhibitor of the relaxation responses to electrical stimulation than was the nucleotide. That 5 -hydroxytryptamine is the more potent inhibitor 


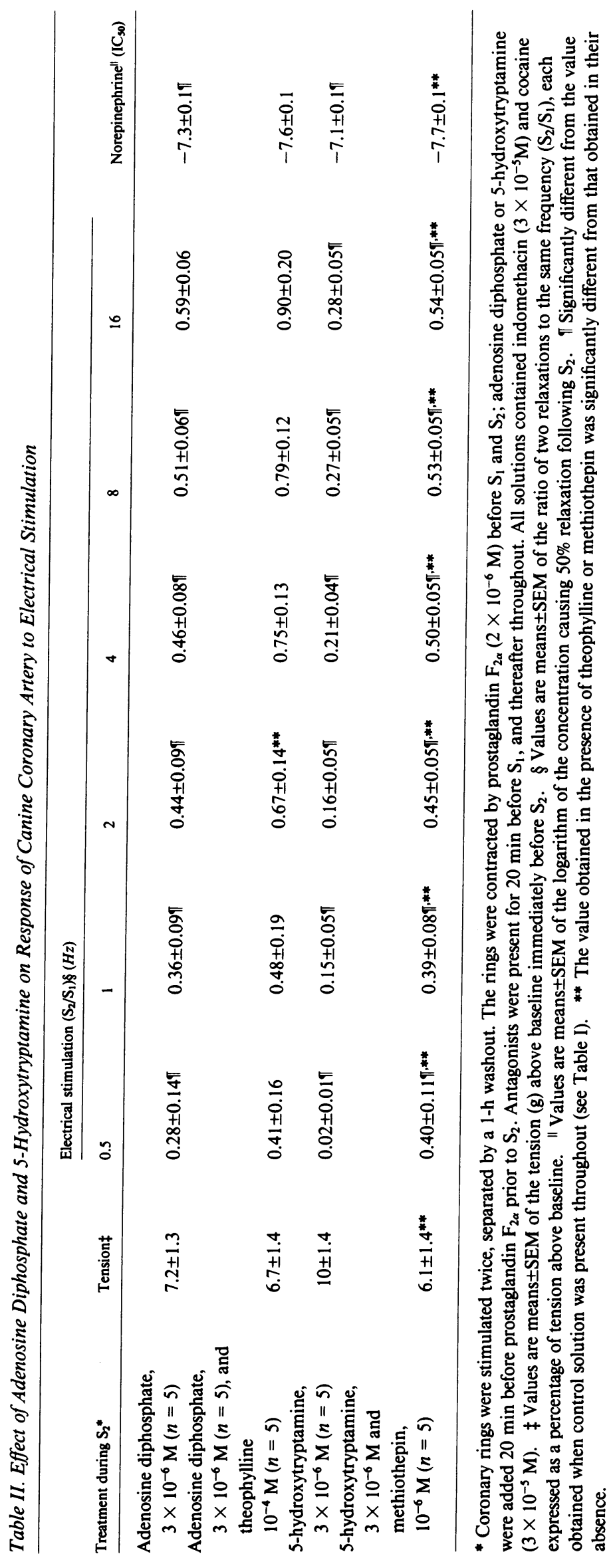




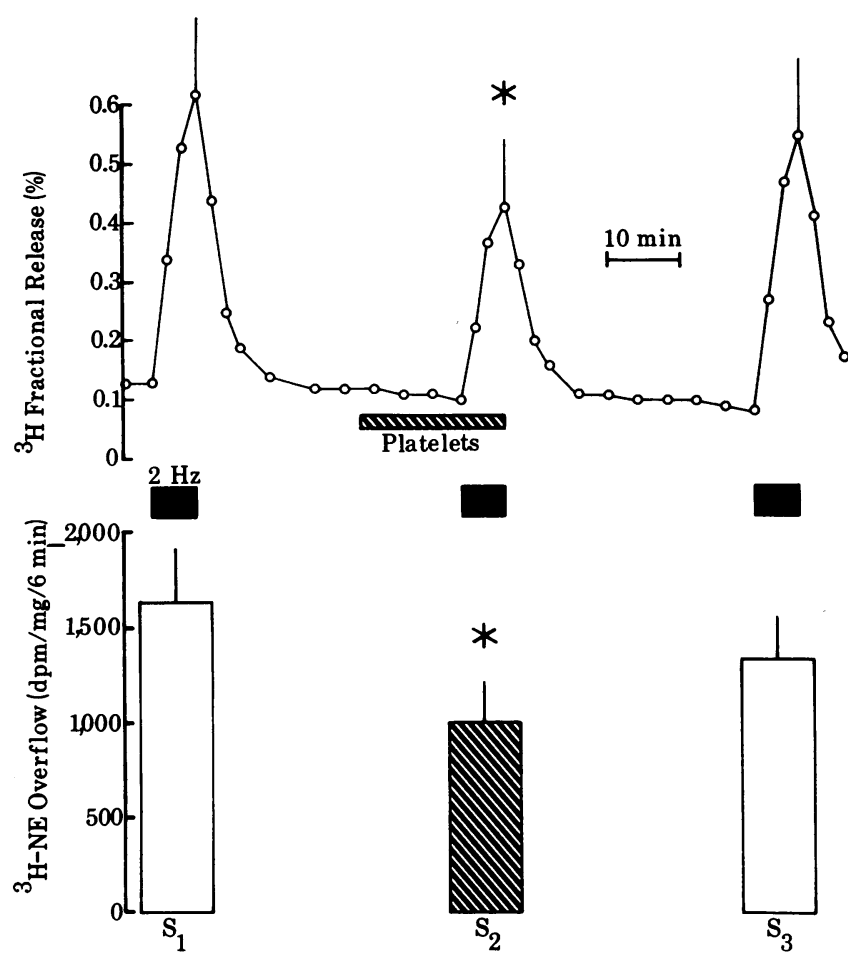

Figure 2. The effect of aggregating platelets on the stimulated overflow of norepinephrine (NE) from canine coronary artery adrenergic nerves. Superfused strips of coronary artery preincubated in $\left[{ }^{3} \mathrm{H}\right]$ norepinephrine were stimulated three times at $2 \mathrm{~Hz}$; before and during the second stimulation, platelets were added to the superfusate. The released tritiated compounds in 2-min collections of superfusate are expressed as a percentage of tissue content of tritium (upper). The evoked overflow of $\left[{ }^{3} \mathrm{H}\right]$ norepinephrine (lower) is the difference between 6-min collections before and during each of the stimulation periods as determined by ion exchange chromatography. The asterisks indicate a significant decrease in overflow of tritiated compounds and $\left[{ }^{3} \mathrm{H}\right]$ norepinephrine in the presence of platelets as compared with that expected from an average of that during $S_{1}$ and $S_{3}$. Basal overflow of $\left[{ }^{3} \mathrm{H}\right]$ norepinephrine before the second stimulation was $82 \pm 17 \mathrm{dpm} / \mathrm{mg}$ tissue per $6 \mathrm{~min}$; this was unaffected by platelets present in the superfusate as it represents $95 \pm 8 \%$ of that expected from an average of the basal overflow before the first and third stimulations.

is supported by the finding that the reduction in the release of radiolabeled norepinephrine caused by adenosine diphosphate in the present study was similar to that caused by a 30 -fold lower concentration of 5-hydroxytryptamine previously determined under identical conditions (11).
The serotonergic antagonist, methiothepin, blocked the reduction caused by 5-hydroxytryptamine of the relaxations of coronary rings in response to electrical stimulation and exogenous norepinephrine. Methiothepin is a relatively non selective serotonergic antagonist $(19,20)$ which may be acting at quite different serotonergic receptors which are located pre- and postjunctionally $(21,22)$ on coronary adrenergic nerves (11) and arterial smooth muscle (6). The antagonism by methiothepin in this study may be ascribed to its ability to: $(a)$ block serotonergic receptors on coronary adrenergic nerves which mediate inhibition of norepinephrine release $(11) ;(b)$ block the contraction caused by 5 -hydroxytryptamine which, like that due to platelets, may have antagonized the relaxation (6); and (c) block alphaadrenoceptors which partially limit beta adrenergic neurotransmission of coronary arteries $(8,11,23)$.

The combination of theophylline and methiothepin served better to antagonize the inhibitory actions of aggregating platelets than either of the two agents alone; this was not as a result of altering the amount of 5-hydroxytryptamine or adenine nucleotides released. It is unlikely that the antagonism of the reduced relaxation response of coronary rings to electrical stimulation and exogenous norepinephrine is nonspecific, since values cited in Table $I$ in the presence of the two antagonists, but in the absence of platelets, were not different from control. Furthermore, only the combination of the two drugs significantly limited the inhibition of norepinephrine release caused by platelets. The latter effect of the combination is unlikely because of an altered release of norepinephrine caused by the antagonists, since methiothepin alone augmented norepinephrine release, but did not decrease the inhibition by platelets. It is possible that adenine nucleotides mediate the prejunctional inhibitory effects of platelets in the presence of methiothepin alone, and conversely, that 5-hydroxytryptamine mediates those in the presence of theophylline alone. This would suggest that in the concentrations released by platelets, adenine nucleotides and 5-hydroxytryptamine are of similar potency. That another vasoactive agent released by platelets is responsible for the residual inhibition in the presence of the combination of the two antagonists cannot be excluded, but this residual inhibition was similar to that observed in the presence of theophylline for a concentration of adenosine diphosphate comparable with that released by platelets. The evidence that both adenine nucleotides and 5-hydroxytryptamine released from platelets are important mediators of the inhibition of coronary adrenergic neurotransmission rests on: (a) the similar inhibitory effects detęrmined for either agent individually; (b) the measured release by platelets of both agents in concentrations which are vasoactive; and $(c)$ the reduction in the inhibitory effects of platelets by antagonists which significantly prevent the

Table III. Effect of Methiothepin and Theophylline on Release of $\left[{ }^{3} \mathrm{H}\right]$ Norepinephrine from Canine Coronary Artery Due to $2 \mathrm{~Hz}$ Electrical Stimulation

\begin{tabular}{|c|c|c|c|c|}
\hline & $\begin{array}{l}\text { Control solution } \\
(n=3)\end{array}$ & $\begin{array}{l}\text { Methiothepin, } 10^{-6} \mathrm{M} \\
(n=5)\end{array}$ & $\begin{array}{l}\text { Theophylline, } 10^{-4} \mathrm{M} \\
(n=5)\end{array}$ & $\begin{array}{l}\text { Methiothepin, } 10^{-6} \mathrm{M} \\
\text { theophylline, } 10^{-4} \mathrm{M} \\
(n=5)\end{array}$ \\
\hline Evoked $\left[{ }^{3} \mathrm{H}\right]$ norepinephrine* overflow & $1630 \pm 275$ & $4636 \pm 561 \ddagger$ & $1712 \pm 377$ & $3144 \pm 1098$ \\
\hline
\end{tabular}

\footnotetext{
* Values are means \pm SEM of the stimulation-evoked overflow of $\left[{ }^{3} \mathrm{H}\right]$ norepinephrine $(\mathrm{dpm} / \mathrm{mg}$ tissue per $6 \mathrm{~min})$ during the first of three 6-min stimulations of superfused longitudinal strips of canine coronary artery. The number of animals from which strips were studied $(n)$ is shown in parentheses. Antagonists were present throughout the washout period and stimulation. All solutions contained cocaine $\left(3 \times 10^{-5} \mathrm{M}\right)$ and indomethacin $\left(3 \times 10^{-5} \mathrm{M}\right)$. The basal overflow of $\left[{ }^{3} \mathrm{H}\right]$ norepinephrine immediately before electrical stimulation was $104 \pm 12 \mathrm{dpm} / \mathrm{mg}$ tissue per $6 \mathrm{~min}$ and was not significantly altered in the presence of antagonists. ¥ Significantly greater than control solution. The value obtained in the presence of methiothepin and theophylline was not significantly different from that in the presence of methiothepin alone $(P>0.2)$.
} 


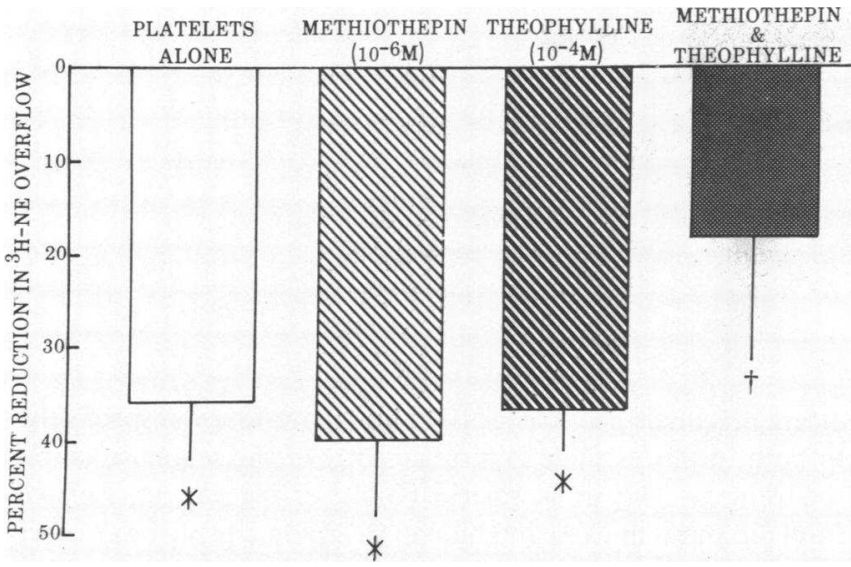

Figure 3. Effect of theophylline and methiothepin on prejunctional adrenergic inhibition caused by aggregating platelets. Superfused strips of coronary artery were preincubated with $\left[{ }^{3} \mathrm{H}\right]$ norepinephrine (NE) and stimulated three times at $2 \mathrm{~Hz}$ in the presence and absence of antagonists; before and during the second stimulation platelets were added to the superfusate. The superfusate collected before and during each stimulation was subjected to ion exchange chromatography to determine the amount of intact $\left[{ }^{3} \mathrm{H}\right]$ norepinephrine overflowing the tissue. Data represent the means \pm SEM of the reduction in norepinephrine overflow which occurred during the second stimulation, expressed as a percentage of the overflow expected from an average of that which occurred during the first and third stimulations. The asterisks denote the significant reduction in stimulated overflow of $\left[{ }^{3} \mathrm{H}\right]$ norepinephrine caused by platelets alone, or when theophylline or methiothepin were present throughout the superfusion. The cross denotes the significant attenuation by a combination of both theophylline and methiothepin of the reduction in $\left[{ }^{3} \mathrm{H}\right]$ norepinephrine release due to platelets. Three preparations were exposed to platelets alone, and five each were treated with each antagonist or the combination of the two.

actions of the two agents. A similar conclusion may be made concerning the endothelium-dependent relaxant action exerted by platelets on coronary arteries; that is that both adenine nucleotides and 5-hydroxytryptamine can participate (2-5).

In addition to the direct contractile effect of platelet-released 5-hydroxytryptamine $(2,6)$, and thromboxane $A_{2}(7)$, inhibition of beta adrenergic neurotransmission by 5-hydroxytryptamine and adenine nucleotides could contribute to coronary vasoconstriction at blood vessel sites where platelets aggregate and release these vasoactive substances.

\section{Acknowledgments}

The author thanks Katherine Boris for typing the manuscript and Kevin Zitnay for preparation of the figures. The author is grateful to Bernice Kuca and Keith Tornheim for the performance of the adenine nucleotide assays.

The author is supported by a Clinician-Scientist Award from the American Heart Association and the work was sponsored by the National Institutes of Health grants HL31607 and HL30668, and by a grant-inaid (13-507-834) from the American Heart Association, Massachusetts Affiliate, Inc.

\section{References}

1. Sherry, S., and A. Scriabine. 1974. Platelets and Thrombosis. University Press, Baltimore. 332 pp.
2. Cohen, R. A., J. T. Shepherd, and P. M. Vanhoutte. 1983. Inhibitory role of the endothelium in the response of isolated coronary arteries to platelets. Science (Wash. DC). 221:273-274.

3. Cohen, R. A., J. T. Shepherd, and P. M. Vanhoutte. 1983. 5-hydroxytryptamine can mediate endothelium-dependent relaxation of coronary arteries. Am. J. Physiol. 245:H1077-H1080.

4. Cohen, R. A., J. T. Shepherd, and P. M. Vanhoutte. 1984. Endothelium and asymmetrical responses of the coronary arterial wall. $\mathrm{Am}$. J. Physiol. 247:H403-H408.

5. Houston, D. S., J. T. Shepherd, and P. M. Vanhoutte. 1985. Adenine nucleotides, serotonin, and endothelium-dependent relaxations to platelets. Am. J. Physiol. 248:H389-H395.

6. Cohen, R. A. 1985. Serotonergic contractions of canine coronary artery not mediated by $5-\mathrm{HT}_{2}$ receptors. Fed. Proc. 44:884a (Abstr.)

7. Ellis, E., O. Oelz, L. J. Roberts, N. A. Payne, B. J. Sweetman, A. S. Nies, and J. A. Oates. 1976. Coronary arterial smooth muscle contraction by a substance released from platelets: evidence that it is thromboxane $A_{2}$. Science (Wash. DC). 193:1135-1137.

8. Cohen, R. A., J. T. Shepherd, and P. M. Vanhoutte. 1983. Prejunctional and postjunctional actions of norepinephrine at the sympathetic neuroeffector junction in canine coronary arteries. Circ. Res. 52:16-25.

9. Cohen, R. A. 1985. Platelet-induced neurogenic coronary contractions due to accumulation of the false neurotransmitter, 5-hydroxytryptamine. J. Clin. Invest. 75:286-292.

10. Cohen, R. A., J. T. Shepherd, and P. M. Vanhoutte. 1984. Neurogenic cholinergic prejunctional inhibition of sympathetic beta-adrenergic relaxation in the canine coronary artery. J. Pharmacol. Exp. Ther. 229:417-421.

11. Cohen, R. A. 1985. Serotonergic prejunctional inhibition of canine coronary adrenergic nerves. J. Pharmacol. Exp. Ther. 235:76-80.

12. Verbeuren, T. J., E. Coen, and P. M. Vanhoutte. 1977. Determination of ${ }^{3} \mathrm{H}$-norepinephrine and its metabolites in superfusate from isolated blood vessels. Arch. Int. Pharmacodyn. Ther. 227:171-174.

13. Verbeuren, T. J., W. J. Janssens, and P. M. Vanhoutte. 1978. Effects of moderate acidosis on adrenergic neurotransmission in canine saphenous veins. J. Pharmacol. Exp. Ther. 206:105-114.

14. Caliguri, E., and I. Mefford. 1984. Femtogram detection limits for biogenic amines using microbore HPLC with electrochemical detection. Brain Res. 296:156-159.

15. Olsson, T., H. Gulliksson, M. Palmeborn, K. Bergstrom, and A. Thore. 1983. Methodological aspects on the firefly luciferase assay of adenine nucleotides in whole blood and red blood cells. Scand. J. Clin. Lab. Invest. 43:657-664.

16. Verhaeghe, R. H., P. M. Vanhoutte, and J. T. Shepherd. 1977. Inhibition of sympathetic neurotransmission in canine blood vessels by adenine and adenine nucleotides. Circ. Res. 40:208-215.

17. Burnstock, G. 1978. A basis for distinguishing two types of purinergic receptor. In Cell Membrane Receptors for Drugs and Hormones: A Multidisciplinary Approach. R. W. Straub and L. Bolis, editors. Raven Press, New York. 107-118.

18. Samet, M. K., and C. O. Rutledge. 1985. Antagonism of the positive chronotropic effect of norepinephrine by purine nucleosides in rat atria. J. Pharmacol. Exp. Ther. 232:106-110.

19. Leysen, J. E., F. Awouters, L. Kenis, P. M. Laduron, J. Vandenberk, and P. A. J. Janssens. 1981. Receptor binding profile of R 41468, a novel antagonist at 5- $\mathrm{HT}_{2}$ receptors. Life Sci. 28:1015-1022.

20. Martin, L. L., and E. Saunders-Bush. 1982. Comparison of the pharmacological characteristics of $5-\mathrm{HT}_{2}$ binding sites with those of serotonin autoreceptors which modulate serotonin release. NaunynSchmeideberg's Arch. Pharmacol. 321:165-170.

21. Van Nueten, J. M., J. E. Leysen, F. deClerck, and P. M. Vanhoutte. 1984. Serotonergic receptor subtypes and vascular reactivity. $J$. Cardiovasc. Pharmacol. 6:S564-S574.

22. Richardson, B. P., G. Engel, P. Donatsch, and P. A. Stadler. 1985. Identification of serotonin M-receptor subtypes and their specific blockade by a new class of drugs. Nature (Lond.). 316:126-131.

23. Gothert, M. 1982. Modulation of serotonin release in the brain via presynaptic receptors. Trends Pharmacol. Sci. 3:437-440. 